\title{
Integrating Chinese Culture with Western Culture in EFLT
}

\author{
Classroom \\ Yuti $\operatorname{Ran}^{1 *}$ \\ ${ }^{1}$ School of Foreign Studies, Henan Polytechnic University, Jiaozuo, China \\ *Yuti Ran, E-mail: ranyuti@hpu.edu.cn
}

Received: August 9, 2016

Accepted: August 19, 2016

Online Published: August 24, 2016

doi:10.22158/selt.v4n3p376

URL: http://dx.doi.org/10.22158/selt.v4n3p376

This paper is conducted as a part of research results of the Teaching Reform Project (672307/007/037) and the Doctoral Fund of Henan Polytechnic University (672103/001/155).

\begin{abstract}
In the current climate of internationalization, intercultural communication is rapidly growing in importance. This paper firstly discusses the inappropriateness of current English teaching and the necessity on developing college learners' intercultural competence on the basis of the research results on cultural awareness carried out among learners and teachers in universities home and abroad. Then it explores the teaching strategies on how to cultivate learners' intercultural competence in EFLT classroom. By employing the techniques of presentation, analysis, discussion, comparison and contrast between Chinese culture and western culture in the teaching content, the learners can obtain the knowledge of both cultures, expand their cultural awareness, increase their tolerance of the existence of difference, understand the new and different cultural patterns and develop a perspective of cross-cultural awareness. This progressive procedure on integrating Chinese culture with western culture in EFLT classroom reinterpreted and extended the tradition procedure in culture teaching.
\end{abstract}

\section{Keywords}

integration, Chinese culture, western culture, EFLT classroom

\section{Introduction}

In the current climate of internationalization, intercultural communication is rapidly growing in importance. In China, with the implementation of the "going global" strategy, educators and language teachers have come to consensus on the development of intercultural competence which poses particular challenge for English teaching in China in that it impinges on one of the fundamental aims of language teaching. However, despite the growing awareness among language teachers and students of intercultural competence, the present situation in EFLT classroom does not always ensure to develop 
learners' intercultural competence. This paper explores some strategies for integrating Chinese culture with western culture in EFLT classroom based on the influential theory on intercultural teaching and conducted research at home and abroad.

\section{The Present Situation of English Teaching in China}

There is no doubt that English teaching in China has made remarkable progress since China was open to the world in the early 1980s. A set of policy and innovation of syllabus have pushed the improvement of English teaching. However, there are still some dissatisfaction and frustration in English teaching. On the one hand, partly due to exam-oriented teaching at different level, English teaching lays emphasis on linguistic knowledge which can help learners acquire high points in examinations, even for college learners because the certifications of CET4 and CET6 are still required as one of the most important qualifications for graduates to obtain a satisfactory job. In such situation, English teaching in China emphasizes on learners' linguistic competence while ignoring their communicative competence, let alone their intercultural competence. On the other hand, partly due to the innovation of syllabus, the contents of textbook are mostly drawn from western magazines, newspaper articles, journals and novels, etc. These materials actually open a new world to Chinese learners. However, they closely relate to western culture involving the western philosophy, value, belief, ideas, customs and rituals. So the cultures taught in English class are actually cultures of the west, while China's own cultures are neglected. These two situations all led to the obstacles of successful communication. The former resulted in so-called "dumb" English. Learners have mastered a large number of vocabulary and grammar, but they do not know how to express themselves freely and appropriately. The latter, due to the lack of balance between western and Chinese culture, results in difficulty in communication with foreigners when talking about our native culture in English. These two ways of English teaching are therefore no longer appropriate, which cannot meet the purpose of modern language teaching and satisfy learners' needs of communicating with people from different culture background in the future. According to Michael (1997), language teaching has a crucial role to play in ensuring that communication in the emerging world community is fully multilingual and multicultural which requires us to broaden our perspectives and move towards a more intercultural practice of language teaching. Meanwhile, many scholars and language educationalists at home and abroad stress the cultivation of capability in one's own culture (Shirley, 1990; Byram \& Morgan, 1994; Brislin \& Yoshida, 1994; Byram, 1997; Hu \& Gao, 1997; Cao \& Lu, 2007; Liao, 2010, etc.). Considering the present situation of English teaching in China, this paper strongly recommends that Chinese culture be integrated with western culture in English class in order to develop learners' intercultural competence. 


\section{The Development of Intercultural Communication Competence}

Since the term "communicative competence" was first brought up by Hymes in 1971, it has been enriched in recent years. Among the large number of literature on it, one of the most representative and influential conceptions was put by Byram. In his introduction to Developing the Intercultural Dimension in language Teaching, he defines the components of intercultural competence as "knowledge, skills and attitudes, complemented by the values on holds because of one's belonging to a number of social groups, value which are part of one's belongs to a given society" and the basis of it as "the intercultural attitudes, curiosity and openness, readiness to suspend disbelief about other cultures and belief about one's own" (Byram, Gribkova, \& Starkey, 2002). From his illustration, it's obvious that the development of one's intercultural competence not only involves the awareness and knowledge of the target culture, but also that of the native culture.

Meanwhile, the study on learners' intercultural competence was carried out among Chinese scholars and educationalists. Wen (1999) proposed a model of intercultural communicative competence in the perspective of college English teaching. She classifies the components of intercultural competence into three levels: sensitivity, tolerance and flexibility. The learners first should be sensitive, get to know the difference between target culture and native culture, train their awareness of cultural discrepancy. The more the learners know the cultural discrepancies, the more easily they can accept and understand the foreign cultures. The flexibility focuses on two kinds of abilities: one is the ability to adjust one's communicative behaviour in terms of the communicator's cultural backgrounds and the cultural environment where the intercultural communication take place, the other is the ability to handle the communicative conflict aroused by cultural discrepancy properly. Zhong and Fan (2000) proposed the critical competence of cultural creativity, which involves comprehending competence, evaluating competence and incorporating competence. Comprehending competence enables the learner to understand a culture with both cognitive insight and affective empathy. Evaluating competence requires one to assess available information with a critical mind. And incorporating competence means integrating new information with known information into an own mental schemes that will guide his behaviour. As for the intercultural awareness, it is a kind of comprehending competence which contains the understanding of both target culture and native culture. Because cultural learning is an interactive process, target culture learning contributes to the deep understanding of native culture and vice visa.

Although there are some differences in components of intercultural communicative competence, the scholars have reached a common agreement that both target culture and native culture are crucial for developing learner's intercultural communicative competence.

As for intercultural teaching, Humphrey (2002) has noted, "the intercultural approach focuses on building awareness in learners that people of other cultures have different perceptions of the outside world by helping learners explore their own perceptions", in that learners own culture provides them with a cognitive framework for perceiving the world around them. Willis called the capability in one's own culture the bricks and mortar of our own most commonplace understanding. Chinese cultures 
which focus on collectivism is different from western cultures which emphasize on individualism. If learners have no system on our own culture which embraces a number of assumptions about how the world is constructed, when they are exposed to other culture, there will be leading to intercultural misunderstanding and miscommunication.

\section{The Research and Discussion}

In order to compare the views on the function of native culture in authentic communication situation, the research was carried out in two stages at home university and UK university. The first stage was carried out in October, 2013 at Henan Polytechnic University, PRC, and the second, in May, 2014 at University of Portsmouth, UK. The participants were chosen at random involving the learners and the teachers in both universities. 124 learners and 4 English teachers in HPU and 20 Chinese learners, 3 Chinese visiting scholars and 2 British lecturers in the University of Portsmouth were invited to discuss their opinions and experiences of their own cultures in English learning and teaching because participants at home and abroad could have different experience on intercultural communication because of different context.

The participants were asked to complete a short biographical questionnaire, including details of their English learning and teaching, experience of interacting with foreigners and time length learning abroad. Open questions were designed to stimulate discussion, which includes 4 sections: the necessity of Chinese culture in English learning and teaching, general views of linguistic competence and intercultural competence, experience on English learning in class and communicating with foreigners, the function of Chinese culture in effective communication.

The data highlighted the importance of Chinese culture teaching and learning in English class. Eighty percent of learners at home university and ninety-five percent of learners abroad emphasized the importance of Chinese culture in English class. One student at Henan Polytechnic University noted, "Learning Chinese culture in English class helped me a lot when I communicated with my foreign teachers". And one student at the University of Portsmouth not only listed the benefits of Chinese culture learning, such as improving English skills, facilitating successful communication with native people, facilitating western people better understanding of China, etc., but also described his embarrassment and frustration learning abroad due to his lack of Chinese culture. All the teachers approved that Chinese culture be integrated with western culture in English class. One teacher at Henan Polytechnic University expressed his concern as this, "our learners know a great deal about the west, but very little about our own country, which is sad for English teaching and our country". The lecturers at the University of Portsmouth noted that some international learners in their class did not know how to introduce their own culture in English and lacked the capacity to communicate with their western peers effectively.

With regard to linguistic competence and intercultural competence, home learners paid more attention to linguistic competence rather than intercultural competence while learners abroad put equal 
importance on both. The academic staff agreed that English teaching should focus on both linguistic competence and intercultural competence. However, they still expressed their worry that present English teaching could not guarantee the best results because of the system of examination and fixed textbooks.

With respect to experience on English learning and communicating with foreigners, the majority of participants at home university agreed that linguistic competence was prior to intercultural competence because it laid a solid foundation for their further learning. However, two participants expressed that too much emphasis on linguistic competence and neglect of intercultural competence resulted in learners' poor ability of communication. All participants learning abroad laid equal importance on linguistic competence and intercultural competence. One participant noted, "Without enough linguistic knowledge, I don't know how to communicate with my foreign peers. Without intercultural competence, I don't know what to say when conversing with my foreign peers". From the experience of participants on English learning and communicating with foreigners, it's clear that linguistic competence is the premise of communication and intercultural competence can ensure the communication between people from different cultural background go on smoothly.

The majority of participants cited that they knew knowledge of Chinese culture while they didn't know how to express it in English. All the participants abroad highlighted their frustration when they lived in UK and interacted with the native people in that they didn't know much knowledge of home culture. It seems that, for the learners abroad, being cut adrift from their own culture mean a huge of insecurity. Culture baggage can act as a safety net (Kam, 2005). Meanwhile, three participants learning in UK pointed out the major obstacle in effective communication was due to the lack of western culture knowledge. It was suggested that teachers should provide the skills to enable learners to adapt to new environment as soon as possible, which involves understanding both host culture and home culture, how these cultures can be both beneficial and harmful.

Therefore, in view of these findings, it seems that the traditional English teaching in China is no longer appropriate because of lack of cultural synergy. Some strategies should be adopted in EFLT classroom to supplement the teaching material and develop learners' intercultural competence.

\section{Strategies to Develop Learners' Intercultural Competence}

It's evident that there is among learners and teachers at home and abroad a growing awareness of the significance of integration Chinese culture with western culture in EFLT classroom. As for intercultural competence cultivation in EFLT classroom in China, the first and perhaps the most important step to be undertaken is to get learners familiar with both cultures. Learners can use English to introduce western culture and Chinese culture as well.

The second step is to develop learners' critical thinking capacity by which learners are willing to see things in relative perspective and enjoy similarities and differences between two cultures.

The last but not the least step is to develop learners' awareness to open to others and be self-confident. 
However, most textbooks adopted in college classroom, whether complied by Chinese authors or foreign counterparts, focus on introducing western culture, which only meet Chinese learners needs to learn western culture while cannot satisfy the purpose of cultivating intercultural communicator. This situation set a high demand for English teachers in China. The textbook serves as the core of the teaching material and all activities and tasks spin off from the text. Therefore, English teachers in China should use the textbook creatively based on the content of teaching material and their relevant knowledge of Chinese culture, adopt some teaching strategies to integrate both cultures appropriately, develop learners' intercultural awareness and provide learners skills to learn themselves. The following sample is a demonstration on how to develop learners' intercultural competence by integrating Chinese culture with western culture in EFLT classroom. The text is Diogenes and Alexander, excerpted from Book Three, Contemporary College English published in Foreign Language Teaching and Research Press. A progressive learning module structure is used as one of the forms of graphic organizers to illustrate how to teach both western culture and Chinese culture. At the bottom, the progressive graph represents what the learners learn according to the content of text in EFLT classroom. On the left, it represents how the learners develop both linguistics knowledge and intercultural competence. In the middle, it represents the learners' behaviour on their learning.

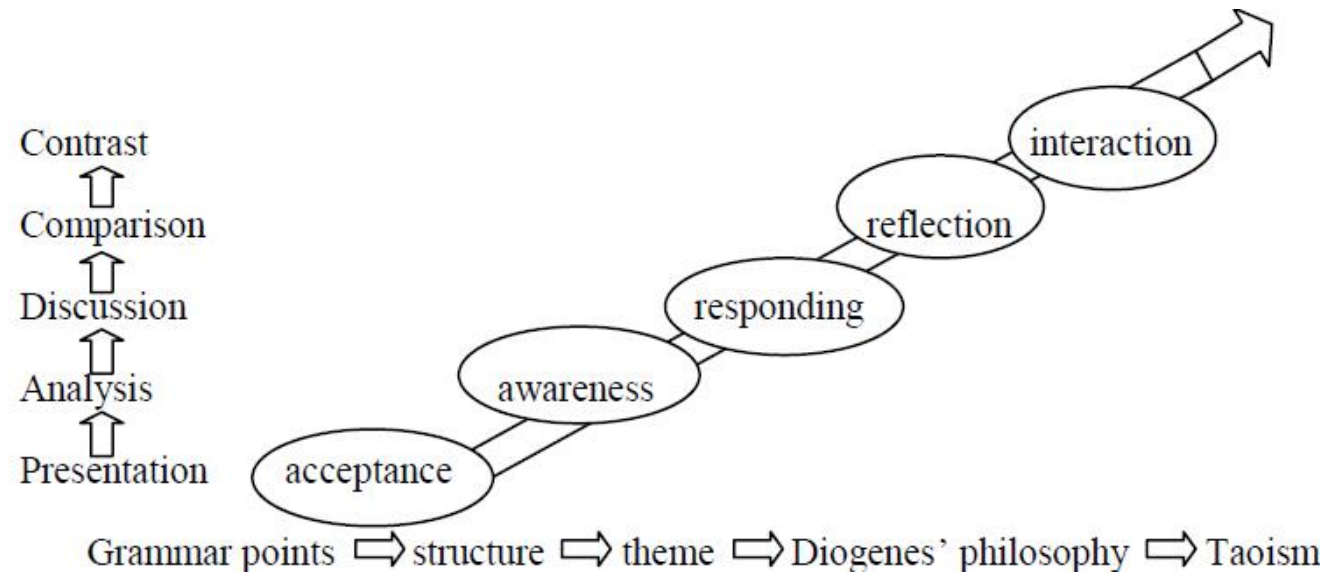

Figure 1. Technique and Procedure of Cross-Culture Teaching

Based on learners' linguistic knowledge and the content of teaching material, knowledge of cultural differences and similarities is the focus in EFLT classroom. Comparison and contrast is an effective way to achieve teaching purpose in this unit. The techniques and procedure of teaching are demonstrated as the following:

1) Present the grammar points which involve vocabulary, sentence patterns by demonstration, elicitation, answer and question etc., which set the premier of further learning.

2) Analyze the structure of the text and discuss the theme of the text. By analysis and discussion, learners get a comprehensive understanding on the text and develop their analytical abilities.

Published by SCHOLINK INC. 
3) Complete the categories of Diogenes' philosophy which involves his belief, attitudes, values and behaviours by group discussion, which made learners understand the content of text.

4) Oral practice on the relevant Chinese philosophies by group discussion and task-based activity, during which learners can recall their knowledge on Chinese culture, share their information and complete the task in cooperation.

5) Compare and contrast western philosophies with Chinese philosophies, reach a conclusion of their differences and similarities and get a full understanding of knowledge of both philosophies.

6) Guide learners to analyze ours and otherness by questions and answers which help them to develop a critical awareness of cultural identity.

7) Assign learners task to collect more information on beliefs of western philosophers, such as Socrates, Plato and Aristotle who are referred in the text and that of Chinese philosophers, such as Laozi and Zhuangzi who are representative of Taoism.

Such progressive procedure is different from traditional English teaching we discussed above which laid emphasis on grammar points or on western culture. Traditional procedures are not rejected but are reinterpreted and extended. Although the contents of teaching material centre on linguistic knowledge and western culture, the teaching points are supplemented by integrating Chinese culture. In this unit, by comparative study of beliefs, attitudes, behaviours, values of western philosophers and Chinese philosophers, learners can obtain knowledge of philosophy of both sides, expand their cultural awareness, increase their tolerance of the existence of difference, understand the new and different cultural patterns and develop a perspective of cross-cultural awareness that recognises cultural differences and fosters understanding of the strength of diversity. In addition to comparative study, the types of tasks that develop learners' intercultural competence in EFLT classroom include discussions, case studies, surveys, presentations, problem solving and debates, essay and report writing etc. Different techniques can be adapted in class based on the content of text in order to provide learners knowledge of different cultures and develop them skills to communicate effectively. What is more, in this modern society, new technology can be fully developed to create a supportive learning environment for learners.

\section{Conclusion}

Integrating Chinese culture with western culture is based on the belief that our own culture has provided us with a cognitive framework for perceiving the world around us. Linguistic competence cannot always guarantee effective communication and only serve the tool of communication. In the current climate of internationalization, Chinese learners need to develop an awareness of the importance of how their own values, beliefs, perceptions and cultural norms can assist or hinder the communication process. Both Chinese culture and western culture are equally valued and grow and adjust together. Learners in EFLT classroom are equipped with not only the structural aspects of the language, but with the cultural knowledge and intercultural awareness. Cultural learning, like all 
learning, should be seen as a process. It could be seen as a series of stages along the road to the development of intercultural communicative skills and personal change; or, alternatively, as a "path leading from ethnocentrism, finding only value, right, logic in one's own cultural patterns, to varying stages of awareness, understanding, acceptance, and a variety of outcomes" (Damen, 1987). Therefore, development of intercultural awareness is a life-long process.

\section{References}

Brislin, R. W., \& Yoshida, T. (1994). Intercultural Communication Training: An Introduction. Thousand Oaks, CA: Sage.

Byram, M. (1994). Teaching and Learning Language and Culture. Great Britain: WBC.

Byram, M. (1997). Cultural awareness as vocabulary learning. Language Learning Journal, September(16), 51-57. http://dx.doi.org/10.1080/09571739785200291

Byram, M., \& Risager, K. (1999). Language Teachers, Politics and Cultures. Multilingual Matters Ltd.

Cao, G., \& Lu, H. (2007). Dissemination of Native Culture in Foreign Language Teaching. Journal of Xinyang Agricultural College, 2, 140-143.

Damen, L. (1987). Culture Learning: The Fifth Dimension in the Language Classroom Reading. MA: Addison-Wesley.

Hu, W. Z., \& Gao, Y. H. (1997). Foreign Language Teaching and Culture. Changsha: Hunan Education Press.

Hu, W. Z., \& Jia, Y. X. (2006). Preface. In G. M. Chen, \& W. J. Starosta (Eds.), Foundations of Intercultural Communication. Shanghai: Shanghai Foreign Language Education Press.

Humphrey, D. (2002). Intercultural communication: A teaching and learning framework. Paper presented at the conference "Setting the Agenda", University of Manchester, Manchester.

Hymes, D. H. (1972). On Communicative Competence. Philadelphia: University of Pennsylvania Press.

Kam, L. (2005). Gathering cultural knowledge: Useful or use with care? In J. Carroll, \& J. Ryan (Eds.), Teaching International Students (pp. 17-25).

Kelly, M. (1997). Towards an Intercultural Practice of Language Teaching. In National Report on Finland: State of the Art of ICC, TNP Intercultural Communication Workshop, Lille.

Liao, Y. H. (2010). Case Analysis in Intercultural Communication. Beijing: Beijing Institute of Technology Press.

Mckay, S. (2002). Teaching English as an International Language: Rethinking Goals And Approaches. Oxford: Oxford University.

Shirley, A. (1993). Starting with the Self: Capability in one's Own Culture. Paper presented as the result of a Research entitled "Cultural Studies in Advanced Language Learning", run at Thames Valley University.

Wen, Q. F. (1999). Testing \& Teaching Spoken English. Shanghai: Shanghai Foreign Language Education Press. 
Zhang, H. L. (2007). Intercultural Approach to Foreign Language Teaching. Shanghai: Shanghai Foreign Language Education Press.

Zhong, H., \& Fan, W. W. (2000). On intercultural competence cultivation for non-English majors. Foreign Language World, 4, 14-16. 